\title{
Muscarinic Receptor Binding Increases in Anterior Thalamus and Cingulate Cortex during Discriminative Avoidance Learning
}

\author{
Brent A. Vogt, ${ }^{1}$ Michael Gabriel, ${ }^{2}$ Leslie J. Vogt, ${ }^{1}$ Amy Poremba, ${ }^{2}$ Eugene L. Jensen, ${ }^{1}$ Yasuo Kubota, ${ }^{2}$ and \\ Eunjoo Kang ${ }^{2}$ \\ 'Department of Physiology and Pharmacology, Bowman Gray School of Medicine, Wake Forest University, Winston- \\ Salem, North Carolina 27103 and ${ }^{2}$ Department of Psychology, Beckman Institute, University of Illinois, Urbana, Illinois \\ 61801
}

Training-induced neuronal activity develops in the mammalian limbic system during discriminative avoidance conditioning. This study explores behaviorally relevant changes in muscarinic $\mathbf{A C h}$ receptor binding in $\mathbf{5 2}$ rabbits that were trained to one of five stages of conditioned response acquisition. Sixteen naive and 10 animals yoked to criterion performance served as control cases. Upon reaching a particular stage of training, the brains were removed and autoradiographically assayed for ${ }^{3} \mathrm{H}$-oxotremorine- $\mathrm{M}$ binding with $50 \mathrm{nM}$ pirenzepine (OXO-M/PZ) or for ${ }^{3} \mathrm{H}$-pirenzepine binding in nine limbic thalamic nuclei and cingulate cortex. Specific OXO-M/PZ binding increased in the parvocellular division of the anterodorsal nucleus early in training when the animals were first exposed to pairing of the conditional and unconditional stimuli. Elevated binding in this nucleus was maintained throughout subsequent training. In the parvocellular division of the anteroventral nucleus (AVp), OXOM/PZ binding progressively increased throughout training, reached a peak at the criterion stage of performance, and returned to control values during extinction sessions. Peak OXO-M/PZ binding in AVp was significantly elevated over that for cases yoked to criterion performance. In the magnocellular division of the anteroventral nucleus (AVm), OXOM/PZ binding was elevated only during criterion performance of the task, and it was unaltered in any other limbic thalamic nuclei. Specific OXO-M/PZ binding was also elevated in most layers in rostral area $29 \mathrm{c}$ when subjects first performed a significant behavioral discrimination. Traininginduced alterations in OXO-M/PZ binding in AVp and layer la of area $29 \mathrm{C}$ were similar and highly correlated. Elevated OXO-M/PZ binding in area $29 d$ was restricted to layer $\mathrm{Va}$ during all stages of training except in overtraining, and there were no changes in area 24. Specific binding of ${ }^{3} \mathrm{H}$-pirenzepine was unaltered in any limbic thalamic or cortical areas.

Increases in OXO-M/PZ but not pirenzepine binding suggest that binding to $M_{2}$ receptors is altered throughout discriminative avoidance learning. It is possible that part of the change in cingulate cortex is associated with thalamic neu-

\footnotetext{
Received Aug. 21, 1990; revised Dec. 27, 1990; accepted Jan. 3, 1991.

This research was supported by the Air Force Office of Scientific Research under the auspices of Grants 89-0044 and 89-0045.

Correspondence should be addressed to Brent A. Vogt, Department of Physiology and Pharmacology, Wake Forest University, 300 Hawthorne Road, Winston-Salem, NC 27103.

Copyright (C) 1991 Society for Neuroscience $0270-6474 / 91 / 111508-07 \$ 03.00 / 0$
}

rons because the anteroventral nucleus projects to layer I of area 29 and has neurons that synthesize $M_{2}$ receptors. Finally, because training-induced neuronal activity paraliels changes in OXO-M/PZ binding, elevated $\mathrm{M}_{2}$ binding may be a prerequisite for this activity in parts of the limbic system.

There is currently great interest in understanding the neural mechanisms that underlie mammalian learning and memory. Major strides have been made in documenting the mechanisms of synaptic plasticities such as long-term potentiation (for reviews, see Bliss and Lynch, 1988; Brown et al., 1988). However, the behavioral relevance of long-term potentiation is unknown because it has not been directly linked to activity in brain circuits with an identified relevance to learning.

Wc have devcloped an approach to the neurobiology of mammalian learning and memory that focuses on neurochemical changes induced in parts of the limbic system that are known to be critical for a clearly defined behavior. It is well established that ablation of cingulate cortex or limbic thalamus disrupts performance of avoidance behavior (Peretz, 1960; Lubar and Perachio, 1965; Lubar, 1964; Gabriel et al., 1989). The acquisition of this behavior is crucial for survival because it involves the prediction and avoidance of aversive and possibly lifethreatening stimuli. In one version of this task, rabbits learn to avoid a mild foot-shock unconditional stimulus by stepping in a running-wheel apparatus in response to a warning tone sounded $5 \mathrm{sec}$ before the unconditional stimulus. The rabbits also learn to ignore a different tone that is never followed by the unconditional stimulus. Remarkably, neurons in cingulate cortex and limbic thalamus develop associative changes in activity during training. These changes include both training-induced excitation, that is, increases in firing in response to the warning tone relative to firing obtained when a tone is not paired with foot shock, and training-induced discrimination, that is, increased firing to the positive conditional stimulus over that to the negative conditional stimulus. Thus, training-induced excitation occurs immediately during the first conditioning session in the anterodorsal thalamic nucleus and continues essentially unchanged during the remainder of training. In the laterodorsal, mediodorsal, and anteroventral nuclei, training-induced excitation and discriminative activity develop more slowly, reaching maxima in later stages. In posterior cingulate cortex, discriminative neuronal activity occurs early in training in the deep layers and later in training in the superficial layers (Gabriel et al., 1977, 1980a,b, 1988; M. Gabriel, B. A. Vogt, A. Poremba, Y. Kubota, and E. Kang, unpublished observations). Further- 
more, discriminative neuronal discharges can bc abolished in cingulate cortex by anterior thalamic lesions (Gabriel et al., 1983, 1989).

Because neurotransmitter receptors can be localized to particular cortical neurons and afferents, and because they are dynamic components of the neuronal membrane, these receptors are candidates for regulation throughout the course of behavioral training. Muscarinic ACh receptors, for example, have been experimentally localized in limbic thalamus and cortex, and their in vivo dynamics have been partially documented. Receptors with a high affinity for pirenzepine are referred to as $\mathbf{M}_{1}$ receptors in pharmacological terminology, and they have been localized to the entire dendritic tree of cingulate cortical pyramidal neurons (Vogt and Burns, 1988). The $\mathrm{M}_{2}$ subtype has a low affinity for pirenzepine, and it has been shown that ${ }^{3} \mathrm{H}$ oxotremorine- $\mathrm{M}$ in the presence of $50 \mathrm{nM}$ unlabeled pirenzepine (OXO-M/PZ) is selective for $\mathrm{M}_{2}$ receptors. In addition, more than half of these receptors in superficial layers of cingulate cortex are muscarinic heteroreceptors on the axon terminals of anterior thalamic neurons (Vogt and Burns, 1988; Vogt, 1991). Furthermore, the number of muscarinic receptors can be increased in vivo with chronic administration of antagonists or cholinergic deafferentation lesions (Schiller, 1979; Takeyasu et al., 1979; Ben-Barak and Dudai, 1980; Westlind et al., 1981), while they are decreased in density following chronic administration of cholinesterase inhibitors (Uchida et al., 1979; Ehlert et al., 1980).

The strategy of the present study was to train rabbits in the discriminative avoidance task to various stages of behavioral acquisition. Following training, the binding of ligands to a number of different receptors was evaluated, including the following: $\mathrm{M}_{1}$ and $\mathrm{M}_{2} \mathrm{ACh}, 5-\mathrm{HT}_{1}$, neurotensin, $\mathrm{GABA}_{\mathrm{A}}$, and $\mu$ - and $\delta$-opioid. Use of the coverslip autoradiographic technique and joint counterstaining of the underlying sections allowed for the resolution of changes in binding at the subnuclear and sublaminar level of analysis. Binding of oxotremorine- $M$ was the only instance in which there was a consistent increase in binding in parts of the limbic thalamus and cortex during task acquisition. Futhermore, increases in oxotremorine-M binding had a clear relationship with early- and late-developing neuronal plasticities (M. Gabriel, B. A. Vogt, A. Poremba, Y. Kubota, and E. Kang, unpublished observations). This is the first instance in which training-induced increases in transmitter receptor binding have been reported in behaving animals.

\section{Materials and Methods}

Behavioral conditioning. Male New Zealand rabbits received discriminative avoidance conditioning in a rotating-wheel apparatus that has been previously described (Gabriel et al., 1980a). One- or $8-\mathrm{kHz}$ tones were used as conditional stimuli. The positive conditional stimulus was one of these tones and was followed after $5 \mathrm{sec}$ by a foot shock delivered through the grid floor of the apparatus. The other tone was randomly interspersed with the positive conditional stimulus and was not followed by the unconditional stimulus. Sixty trials with each tone stimulus were given daily. An intertrial interval of $10,15,20$, or $25 \mathrm{sec}$ was randomly chosen. Rabbits were trained to different levels of behavioral discrimination and compared to 16 naive control cases and 10 control cases that were yoked to the average performance of animals that attained a criterion level of performance; that is, they received the same number of conditional and unconditional stimuli for the samc number of days, but there was no pairing of one tone with the unconditional stimulus.

The stages of training and number of animals so trained were as follows: First exposure (FE), the first training session in which one of the two tones was paired with the unconditonal stimulus $(n=10)$; first significant (FS), the session in which the subject first showed a $25 \%$ greater rate of avoidance responding to the positive conditional stimulus than to the negative conditional stimulus $(n=10)$; criterion, two successive days of performance in which the proportion of conditioned responses to the positive conditional stimulus exceeded that to the negative conditional stimulus by $60 \%$ or more $(n=12)$; overtraining (OT), three sessions of training beyond the criterion stage of performance $(n$ $=16$ ); extinction (EX), $2 \mathrm{~d}$ of postcriterion training in which the conditional stimuli were presented without the unconditional stimuli $(n=$ 4). Within 10-70 min of reaching a particular level of performance, the animals were killed with $\mathrm{CO}_{2}$, and their brains were removed, blocked, and frozen to $-80^{\circ} \mathrm{C}$

Receptor binding and autoradiographic techniques. Cryostat sections were cut $16 \mu \mathrm{m}$ thick for cortical blocks and $32 \mu \mathrm{m}$ thick for thalamic blocks and mounted on chrom-alum-coated slides. Sections from the thalamus were cut thicker in order to improve the resolution of thalamic cytoarchitecture and subtle differences among the various limbic thalamic nuclei. Optimal conditions for selective labeling of $\mathbf{M}_{2}$ receptors in cingulate cortex have been reported (Vogt and Burns, 1988) and include the following steps: (1) Sections were incubated for $30 \mathrm{~min}$ in $20 \mathrm{~mm}$ Tris-HEPES buffer with $10 \mathrm{~mm}$ magnesium, $0.1 \mathrm{nM}{ }^{3} \mathrm{H}$-oxotremorine-M (New England Nuclear; specific activity, $84.9 \mathrm{Ci} / \mathrm{mM}$ ), and 50 nM pirenzepine, which was kindly provided by Boehringer Ingelheim, Ltd. Nonspecific binding was determined in a parallel series of sections that were coincubated in $1 \mu \mathrm{M}$ atropine. (2) Sections were washed twice for 2 min each with buffer at $4^{\circ} \mathrm{C}$ and then once for 2 min with $\mathrm{dH}_{2} \mathrm{O}$ at $4^{\circ} \mathrm{C}$. (3) Sections were quickly dried and exposed to emulsion-coated coverslips for 2-3 months, and then the emulsion was developed and the underlying sections stained with thionin. Binding of ${ }^{3} \mathrm{H}$-pirenzepine involved incubation of the sections in $15 \mathrm{~nm}{ }^{3} \mathrm{H}$-pirenzepine (New England Nuclear; $83 \mathrm{Ci} / \mathrm{mM}$ ) in Krebs-Henseleit buffer for $70 \mathrm{~min}$ at $25^{\circ} \mathrm{C}$ followed by two washes of $3 \mathrm{~min}$ each in buffer at $4^{\circ} \mathrm{C}$. Nonspecific binding was also determined with $1 \mu \mathrm{M}$ atropine. Binding of other ligands to subsets of these cases was analyzed. Because no alterations in binding could be detected throughout the course of training, the details of each protocol will not be restated here. Each of these other protocols has been previously described: muscimol (Vogt and Hedberg, 1988), (DAla-NMe-Phe-Gly-ol)-enkephalin and (2-D-penicillamine, 5-D-penicillamine)-enkephalin (Plager and Vogt, 1988), serotonin (Crino et al., 1990), neurotensin (Young and Kuhar, 1981), and para-aminoclonidine (Unnerstall et al., 1984). Approximately 37,400 sections were processed for cingulate cortex and 24,600 prepared for the thalami of these 82 cases.

Quantitative and statistical methods. The location of $2500-\mu \mathrm{m}^{2}$ fields for grain counting in the autoradiographs was determined in a particular nucleus or layer with bright-field optics in the Nissl-stained sections. The subdivisions of rabbit thalamus are essentially the same as those previously studied in rat thalamus (Sikes and Vogt, 1987). The rabbit thalamus, however, also contains a lateral magnocellular nucleus, which has extensive connections with cingulate cortex (Vogt and Sikes, 1990). The cytoarchitecture of areas 24 and 29 has been described for rabbit cingulate cortex (Vogt et al., 1986) and was used in the present study to characterize the laminar distributions of ligand binding in each of these areas. Once a nucleus or layer was identified, dark-field optics were used to detect single silver grains with an image analysis system (Image Technology model 1000, Donsanto Corp., Natick, MA). Miscounts due to overlapping grains were visually corrected. Grain densities in three sections of total ligand binding were counted and a mean calculated. Nonspecific binding in two sections coincubated in a blocker was also calculated, and the resulting mean was subtracted from total binding to determine specific binding. Binding in thalamus and cortex was determined by different individuals, and neither was aware of the level of behavioral training for each case. Cases were prepared in four separate experiments, and all cases in each experiment were processed at one time to reduce variabilities in the data due to processing. These cases were then standardized between experiments. Thus, if grain density in one experiment was slightly higher in a nucleus or layer of the naive control cases, specific binding for this latter series was reduced in all control and behaviorally trained cases by an amount based on the differences between the controls. It is important to note that the elevated $\mathrm{OXO}-\mathrm{M} / \mathrm{PZ}$ binding reported for animals trained to the first significant stage occurred in all experiments and was usually statistically significant within a single experiment. Specific binding by thalamic nucleus or cortical layer was evaluated, with mean \pm SEM, graphics, and ANOVA calculated for the main effect of training levels. The significance of 


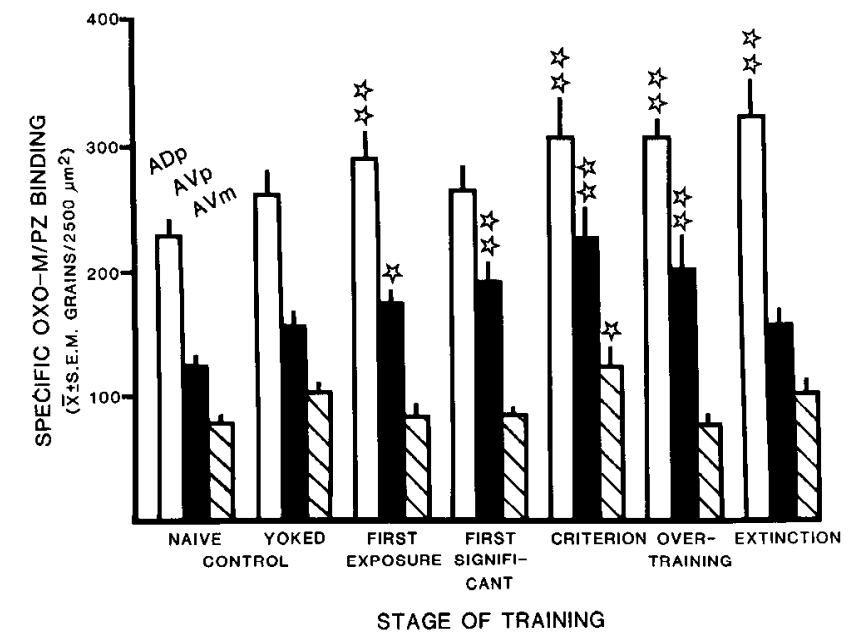

Figure 1. Specific binding of OXO-M/PZ throughout the course of training in three thalamic nuclei. Earliest changes occurred in ADp (open columns) with a small increase also in AVp (solid columns) during the FE stage of training. Binding of OXO-M/PZ in AVp most closely paralleled behavioral performance because it progressively increased to a plateau during criterion performance and then returned to control values during EX training. Specific binding in AVp following criterion performance was significantly different from that for control cases yoked to the same stage of performance. Binding in AVm (hatched columns) increased late in training during the criterion stage of performance. Single stars, $p<0.05$ versus naive control cases; double stars, $p<0.01$ versus naive control cases. Error bars represent SEM.

differences among the means following a significant overall $F$ value in the ANOVA was analyzed with protected $t$ tests for multiple comparisons (Couch, 1982; IBM-AT software was produced by Dynamic Microsystems, Inc., Silver Spring, MD). Correlation coefficients were calculated for specific binding in a cortical layer and thalamic nucleus, and linear regressions were performed with a least-squares curve-fitting program (Dynamic Microsystems). The value of $p$ that was accepted as significant was 0.05 , but the most important observations of this study were significant at $p<0.01$.

\section{Results}

\section{Limbic thalamus}

Oxotremorine-M. Specific binding of OXO-M/PZ was evaluated in nine thalamic nuclei: the magnocellular and parvocellular divisions of the anterodorsal nucleus (ADm and $\mathrm{ADp}$, respectively), the magnocellular and parvocellular divisions of the anteroventral nucleus ( $\mathrm{AVm}$ and $\mathrm{AVp}$, respectively), the anteromedial (AM), laterodorsal (LD), lateral magnocellular (LM), and magnocellular and parvocellular divisions of the mediodorsal nucleus (MDm and MDp, respectively). The $F$ ratios were significant for three of the nine thalamic nuclei: $\operatorname{ADp}(F$ $=2.8 ; p=0.026), \mathrm{AVp}(F=3.4 ; p=0.009)$, and $\mathrm{AVm}(F=$ $4.0 ; p=0.004)$. Alterations in specific $\mathrm{OXO}-\mathrm{M} / \mathrm{PZ}$ binding in these nuclei that were associated with the training conditions are shown in Figure 1. Relative to naive control cases, ADp had the earliest and most robust increase in binding during the stage of first exposure. Although binding in the cases trained to FS behavioral response did not differ from that for naive controls, binding during criterion levels of performance, $\mathrm{OT}$, and $\mathrm{FX}$ was also elevated. In $\mathrm{AVp}$, binding of $\mathrm{OXO}-\mathrm{M} / \mathrm{PZ}$ progressively increased during training and reached a peak during the criterion stage of performance. This binding was significantly elevated over that both in naive control cases and in animals yoked to criterion levels of performance. During OT, binding in $A V p$ was still elevated, while following EX training, binding was reduced
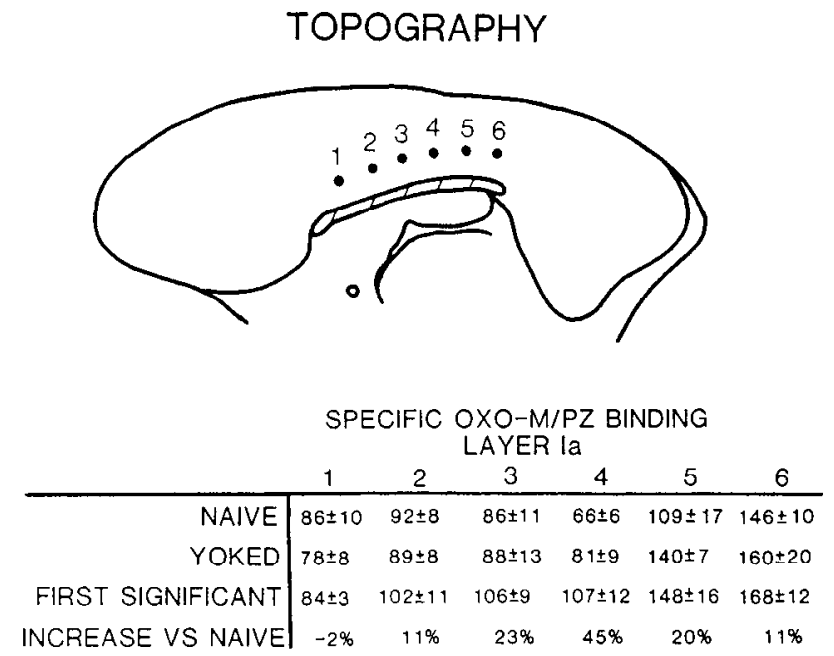

COMBINED EXPERIMENTS

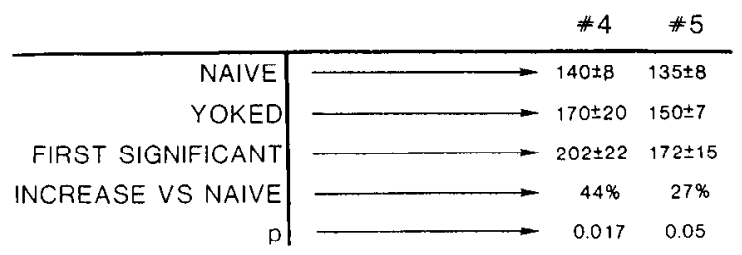

Figure 2. Topographic analysis of $\mathrm{OXO}-\mathrm{M} / \mathrm{PZ}$ binding in layer Ia of control animals and those trained to FS performance $(n=4$ for each group). OXO-M/PZ binding (means $\pm \mathrm{SEM}$ grains $/ 2500 \mu \mathrm{m}^{2}$ ) in control cases increased throughout the rostrocaudal extent of cingulate cortex to reach peak values at level 6 . Furthermore, increases associated with training to the FS stage of performance were greatest in area $29 \mathrm{c}$ at level 4. Level 3 is at the border between areas 29 and 24 , and levels 1 and 2 were in area 24. Combination of animals from three experiments according to the level of sections sampled showed that increases at both levels 4 and 5 were significant when compared to naive control cases and that the increase at level 4 was the greatest.

to control values. In $\mathrm{AVm}$, specific binding of $\mathrm{OXO}-\mathrm{M} / \mathrm{PZ}$ was elevated over naive control values only during the criterion stage of training, and it did not differ from that for yoked control cases. Finally, OXO-M/PZ binding in all three nuclei of the yoked control cases was at an intermediate level between naive control cases and those that completed the FE session. These differences, however, were not significant.

Pirenzepine. There were no differences in specific pirenzepine binding in any thalamic nucleus throughout the course of training.

\section{Cingulate cortex}

Oxotremorine-M. As shown in Figure 2, specific binding of $\mathrm{OXO}-\mathrm{M} / \mathrm{PZ}$ in layer Ia of cingulate cortex in control cases (naive and yoked) progressively increased in the rostrocaudal plane. Levels $1-3$ were in area $24 a$, and levels $4-6$ were in area $29 \mathrm{c}$. In this experiment, binding in layer Ia of these six levels of the control cases was compared to that which occurred in animals that were trained to the FS stage of performance. This latter stage was chosen because $\mathrm{OXO}-\mathrm{M} / \mathrm{PZ}$ binding was elevated in all experiments upon completion of this stage. The largest increase in binding occurred at level 4 in rostral area $29 \mathrm{c}$, with smaller amounts occurring at levels 3 and 5 . The data from this experiment were then combined with that of two previous ex- 


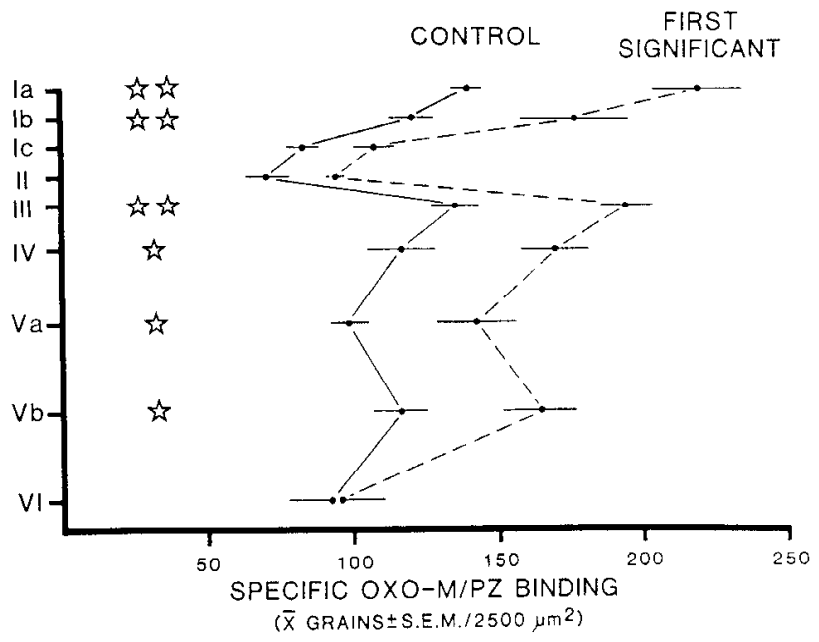

Figure 3. Specific OXO-M/PZ binding at level 4 for cases trained to the stage of FS behavioral discrimination. Multiple-comparison $t$ tests were performed between naive control (illustrated), yoked control (not illustrated), and FS animals. The stars designate layers with significant increases in OXO-M/PZ binding over naive control binding (single stars, $p<0.05$; double stars, $p<0.01$ ). Binding in yoked control cases did not differ from that for naive control cases. Error bars represent SEM.

periments in which only one middle cingulate or caudal cingulate area was available for analysis (naive control, $n=12$; yoked control, $n=10 ; \mathrm{FS}, n=10$ ). As can be seen in Figure 2, combined experiments, the increases in OXO-M/PZ binding in naive versus the FS stage of training in both levels 4 and 5 were statistically significant, with $p$ values of 0.015 and 0.05 , respectively, though the increase at level 4 was much greater than that at level 5. Specific OXO-M/PZ binding in yoked control cases was intermediate between and not significantly different from naive control animals and those trained to the FS stage of performance.

Increases in $\mathrm{OXO}-\mathrm{M} / \mathrm{PZ}$ binding were not restricted to layer Ia. As shown in Figure 3, specific binding of $\mathrm{OXO}-\mathrm{M} / \mathrm{PZ}$ at level 4 increased in most cortical layers following training to the FS stage of performance. Binding for yoked control cases was at an intermediate level for all layers.

Figure 4 shows the changes in OXO-M/PZ binding throughout the course of training in two representative layers of area $29 \mathrm{c}$ for all 78 cases prepared for this study. These layers were chosen for presentation because layer Ia receives anterior thalamic input and layer Va does not (Vogt et al., 1981). The relationship between muscarinic receptor binding in cortical and thalamic structures is considered in the next section. The $F$ and $p$ values were as follows: layer Ia/level $4, F=4.2, p=0.0038$; layer Ia/level $5, F=1.6, p=0.192$; layer Va/level 4, $F=2.4$, $p=0.052$; layer $\mathrm{Va} /$ level $5, F=0.79, p=0.559$. In all experiments, the binding in rostral levels of area $29 \mathrm{c}$ was elevated during the FS stage of training.

Specific binding of OXO-M/PZ was evaluated at three rostral levels of area 29d, as shown in Figure 5. The laminar distribution of binding in control cases of area $29 \mathrm{~d}$ was quite different from that in area $29 \mathrm{c}$. Binding in area $29 \mathrm{~d}$ in layers Ia and Va was highest and about equal in density, while binding in layers $\mathrm{Ib}$ IV and Vb-VI was moderate in density. During training, binding in the rostral two levels of area $29 \mathrm{~d}$ was elevated in layer $\mathrm{Va}$ during the stage of FS behavioral discrimination. An analysis of layer $\mathrm{Va} \mathrm{OXO}-\mathrm{M} / \mathrm{PZ}$ binding throughout training showed that there was an increase in binding at all stages of training,

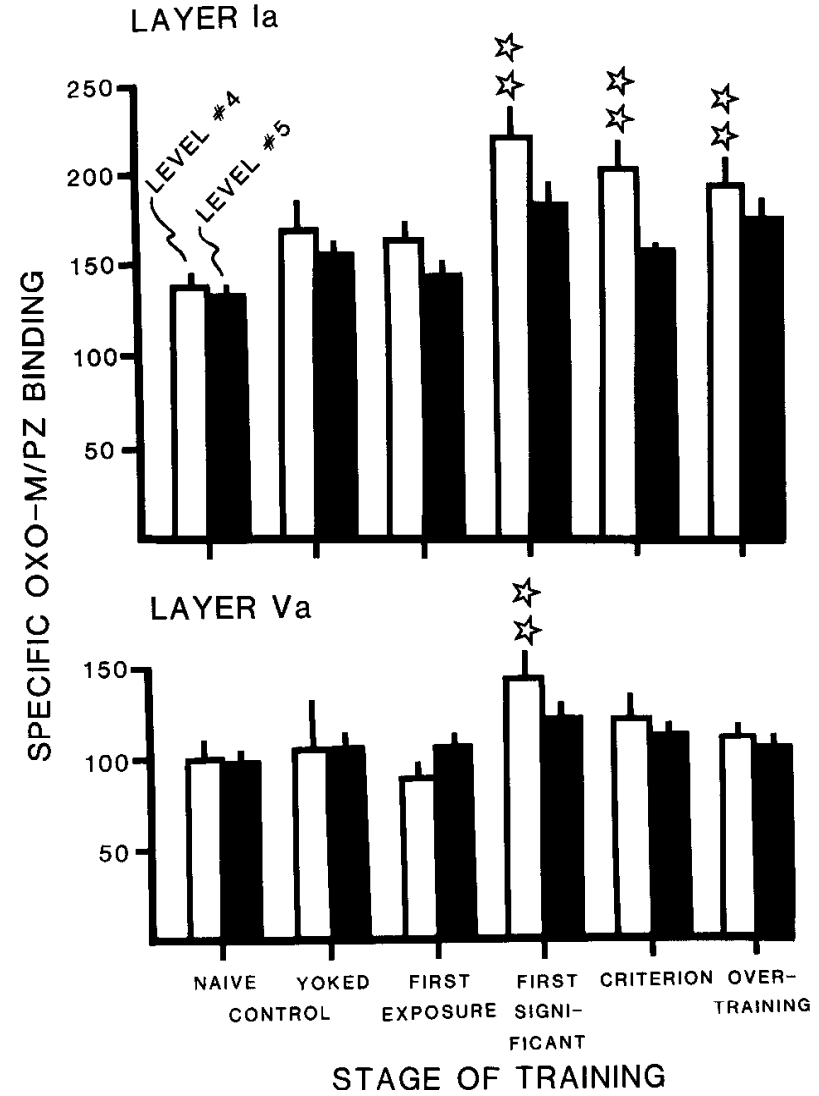

Figure 4. Specific OXO-M/PZ binding (mean \pm SEM grains $/ 2500$ $\mu \mathrm{m}^{2}$ ) is plotted for layers Ia and Va throughout the course of training for levels 4 (open columns) and 5 (solid columns). Increases over control cases occurred in layer Ia at level 4 during the FS and subsequent stages. In layer Va of level 4, the only increase in binding occurred during the FS stage of training (double stars, $p<0.01$ ).

including in yoked control cases, though that in the FS stage was the highest and it returned to control values during OT ( $F$ $=2.51 ; p=0.032$ ).

Pirenzepine and other ligands. In the first of four experiments, there was a major increase in pirenzepine binding in all layers of rostral area 29c. However, in three subsequent experiments, we have been unable to reproduce this finding and so must conclude that pirenzepine binding is stable in cingulate cortex throughout the course of discriminative avoidance training.

Studies were conducted in subsets of these cases to evaluate the binding of other ligands throughout the course of training. These ligands included 5-HT, neurotensin, muscimol, paraaminoclonidine, (D-Ala-NMe-Phe-Gly-ol)-enkephalin, and (2D-penicillamine, 5-D-penicillamine)-enkephalin. There were no consistent changes in the binding of these ligands in any layer of either anterior or posterior cingulate cortex.

\section{Correlations between thalamic and cortical $O X O-M / P Z$ binding}

Because the temporal patterns in OXO-M/PZ binding in thalamus share similarities with those in area $29 \mathrm{c}$, and because these structures are connected, it was necessary to evaluate possible relationships between the binding in the anterior nuclei and area $29 \mathrm{c}$. There were 54 cases available for this joint analysis at level 4 and/or level 5 of area 29c. There was a highly significant correlation between the binding in AVp and that in layer Ia of area $29 \mathrm{c}$ at level $4(n=31 ; r=0.69 ; F=28.6 ; p=0.0001)$. A 

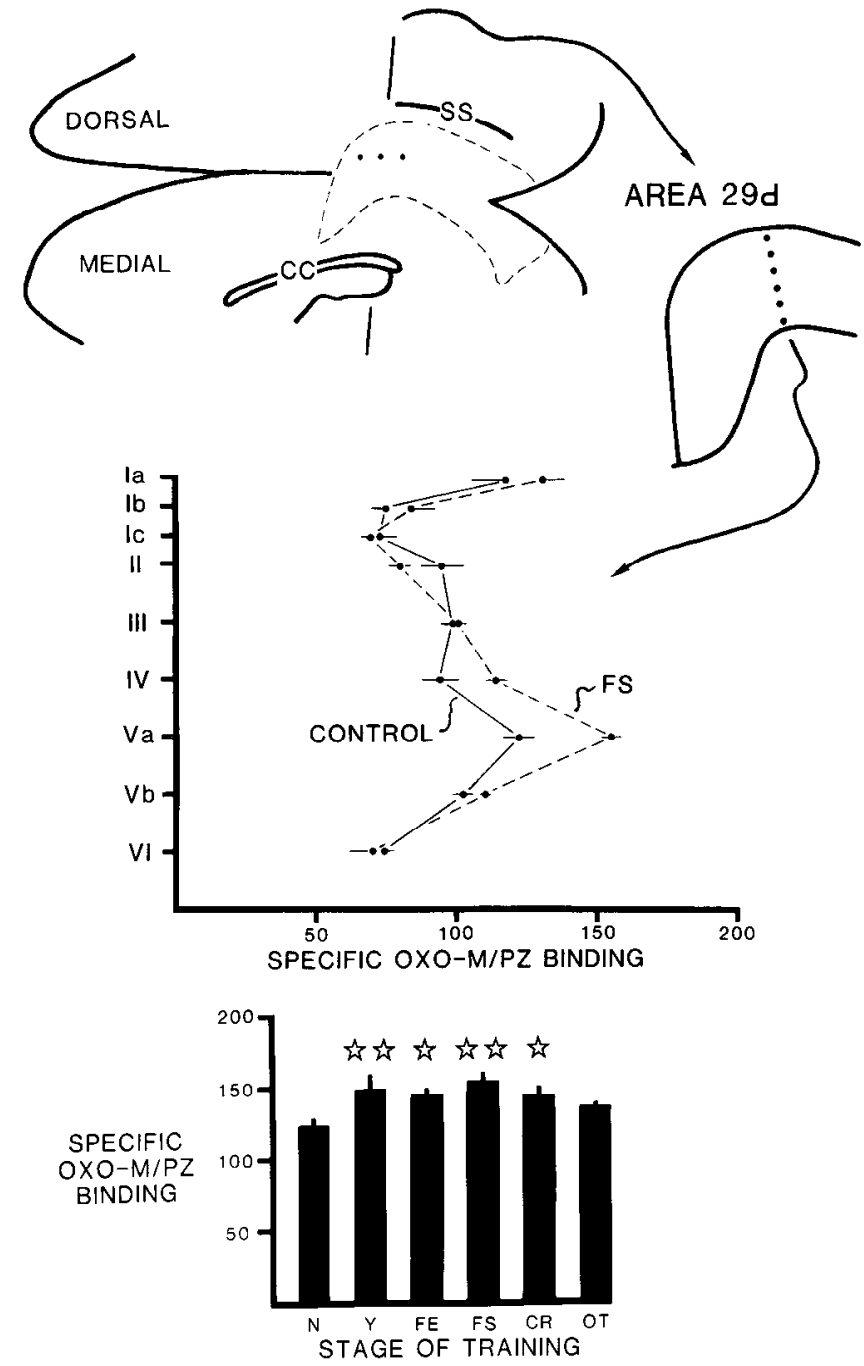

Figure 5. Specific binding of OXO-M/PZ (mean \pm SEM grains $/ 2500$ $\mu \mathrm{m}^{2}$ ) was analyzed at three rostral levels of area $29 \mathrm{~d}$. Although layer Ia binding was high in control cases, it was equal to that in layer Va. During training, only binding in layer Va increased over naive control values. The increased binding occurred in yoked control cases and in animals trained to the FE, FS, and criterion stages. $C C$, corpus callosum; $S S$, splenial sulcus. Single star, $p<0.05 ;$ double stars, $p<0.01$.

graph of specific OXO-M/PZ binding for these cases is presented in Figure 6. The linear regression fit by least-squares analysis to this data was the following:

$$
\text { AVp binding }=11.4+1.05 \text { (Area } 29 \mathrm{c} \text { binding). }
$$

This line is plotted in Figure 6. There was no correlation between $\mathrm{AVp}$ OXO-M/PZ binding and that in layer Ia of area $29 \mathrm{c}$ at level 5 , and $\mathrm{AVp}$ binding in level 4 was not correlated with that in other layers, including layer Va. Finally, the only other thalamic nucleus that had binding correlated with changes in layer Ia of area $29 \mathrm{c}$ was $\mathrm{AVm}$. The correlation of -0.49 was just significant at $p=0.05$.

\section{Discussion}

This is the first demonstration that binding of oxotremorine$M$, under conditions that are selective for $\mathrm{M}_{2}$ ACh receptors, increases in the anterior thalamus and cingulate cortex during discriminative avoidance learning. The time course and nu-

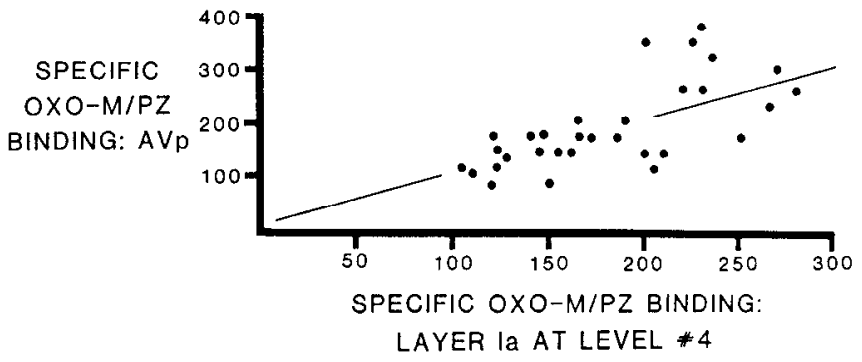

Figure 6. Specific OXO-M/PZ binding in AVp and layer Ia of area $29 \mathrm{c}$ at level 4 was highly correlated. A regression analysis was performed, and a line was fit to the data for these cases.

clear/laminar localization of alterations in binding may be related to the development of training-induced neuronal activity in the same behavioral paradigm. Before addressing these issues, however, it should be noted that receptor-binding observations do not specify whether an alteration in receptor affinity or density has occurred, only that there is a selective increase in binding to $M_{2} A C h$ receptors. In addition, it is unlikely that all $M_{2}$ binding alterations are due to nonassociative features of the conditioning cues such as stress or general arousal. This is unlikely because yoked control cases (i.e., those that receive the same number of conditional and unconditional stimuli over the same number of training sessions as do experimental animals trained to criterion performance with paired stimuli) do not have elevated binding to the same extent as that which occurs in animals that reach the criterion stage of training. In fact, the small increases in $M_{2}$ ACh receptor binding that did occur in the yoked control cases may have been related to learning produced by the control procedure itself, as the conditional stimuli predicted safe periods when unconditional stimuli were not presented.

Increases in $\mathrm{OXO}-\mathrm{M} / \mathrm{PZ}$ binding could be due to either an increase in $\mathrm{M}_{2}$ receptor affinity following altered coupling to GTP-binding proteins or an increase in $\mathrm{M}_{2}$ receptor density subscquent to elevated receptor synthesis. Even though this information is not yet available, the issue can be raised of the cellular basis for increased binding in the anterior thalamus and cingulate cortex. There are three neuronal populations that could be responsible for elevated $\mathrm{OXO}-\mathrm{M} / \mathrm{PZ}$ binding in the anterior thalamus: (1) Neurons in the anteroventral nucleus (AV) synthesize $\mathbf{M}_{2}$ receptors (Buckley et al., 1988). (2) Muscarinic receptors have been experimentally localized to the axons of mammillary body neurons that terminate in AV (Sikes and Vogt, 1987), and these could be $M_{2}$ receptors. (3) Cholinergic neurons in the laterodorsal tegmental nucleus project to $\mathrm{AV}$ (Hoover and Baisden, 1980; Sofroniew et al., 1985), and they could alter the affinity or number of muscarinic autoreceptors during behavioral training. Muscarinic autoreceptors are generally thought to be $\mathrm{M}_{2}$ receptors (Ganguly and Das, 1979; Mash et al., 1985).

Although cortical neurons have not yet been shown to synthesize $M_{2}$ receptors, it is possible that they are induced to express these receptors during behavioral training. Until this question is addressed further, there are three reasons why the $\mathrm{AV}$ in particular may play a major role in regulating muscarinic receptors in cingulate cortex: (1) There was a high correlation between OXO-M/PZ binding in AVp and rostral area 29c. (2) $\mathrm{AVp}$ projects primarily to rostral areas $29 \mathrm{c}$ and $29 \mathrm{~d}$, while $\mathrm{AVm}$ projects mainly to posterior parts of cingulate cortex (L. J. Vogt, B. A. Vogt, and R. W. Sikes, unpublished observations). This 
topography of connections closcly matches the topography of increased $\mathrm{OXO}-\mathrm{M} / \mathrm{PZ}$ binding. (3) The AV has been shown to synthesize $M_{2}$ receptors (Buckley et al., 1988) and so could contribute newly synthesized receptors to cingulate cortex or could alter their affinity via changes in coupling to GTP-binding proteins.

Because the anterior thalamic nuclei do not project to layer $\mathrm{V}$ of posterior cingulate cortex (Vogt et al., 1981), another means of regulating $\mathrm{M}_{2}$ receptor binding in this layer should be considered. Neurons in the diagonal band of Broca project to layer V of area 29 (Saper, 1984), and it has been shown that binding to $\mathrm{M}_{2}$ receptors decreases $\mathrm{ACh}$ release (Ganguly and Das, 1979) and is reduced in cortex following basal forebrain lesions (Mash et al., 1985). Moreover, sodium-dependent, high-affinity choline uptake occurs at cholinergic terminals and may be an index of cholinergic activity (Kuhar and Murrin, 1978). Wenk et al. (1984) reported decreased high-affinity choline uptake in frontal cortex during spatial and active-avoidance learning. Thus, elevated $\mathrm{OXO}-\mathrm{M} / \mathrm{PZ}$ binding in layer $\mathrm{V}$ of areas $29 \mathrm{c}$ and $29 \mathrm{~d}$ may be associated with $\mathrm{M}_{2}$ autoreceptor regulation in cholinergic terminals.

There appear to be some close relationships between the time in training when $\mathrm{OXO}-\mathrm{M} / \mathrm{PZ}$ binding increases and when training-induced neuronal activity occurs. Gabriel et al. (1988; Gabriel, Vogt, Poremba, Kubota, and Kang, unpublished observations) have shown that there is an increase in excitatory discharges in the anterodorsal nucleus during the first session in which the positive conditional stimulus is paired with the unconditional stimulus relative to the preceding session of pretraining. Neurons in $\mathrm{AVp}$ reach peak discharge frequencies and discriminate later in training, when the animal performs at the FS level, and neurons in $\mathrm{AVm}$ reach peak discharge rates and discriminate during the session in which criterion performance of the avoidance task is reached. These differences are similar to the stage-related differences in OXO-M/PZ binding in these areas, and so these two phenomena may occur in tandem in the anterior thalamic nuclei. However, training-induced neuronal activity has also been observed in other limbic thalamic nuclei (Gabriel et al., 1988), while no other nuclei had alterations in $\mathrm{OXO}-\mathrm{M} / \mathrm{PZ}$ binding. Another point of association between training-induced neuronal activity and increased $\mathrm{OXO}-\mathrm{M} / \mathrm{PZ}$ binding occurs in superficial layers of cingulate cortex. Gabriel, Vogt, Poremba, Kubota, and Kang (unpublished observations) have shown that neurons in layers I-III discriminate only when the subjects first perform a significant behavioral discrimination. It was during the FS stage of training that binding of $\mathrm{OXO}$ $\mathrm{M} / \mathrm{PZ}$ was consistently increased. Another note of caution, however, is that early and robust training-induced activity occurs in area 24 but no OXO-M/PZ binding increases occurred in this area. It may be reasonable to conclude that training-induced neuronal activity in parts of the limbic system is at least closely associated with alterations in $\mathbf{M}_{2}$ ACh receptor binding. It is also possible that in some instances the $M_{2}$ binding changes are a necessary prerequisite to training-induced neuronal activity. These clues into the molecular mechanisms of discriminative avoidance learning may provide new directions for research into the bases of learning and memory in general.

\section{References}

Ben-Barak J, Dudai Y (1980) Scopolamine induces an increase in muscarinic receptor level in rat hippocampus. Brain Res 193:309313.
Bliss TVP, Lynch MA (1988) Long-term potentiation of synaptic transmission in the hippocampus: properties and mechanisms. In: Long-term potentiation: from biophysics to behavior (Landfield PW, Deadwyler SA, eds), pp 3-72. New York: Liss.

Brown TH, Chapman PF, Kairiss EW, Keenan CL (1988) Long-term synaptic potentiation. Science 242:724-728.

Buckley NJ, Bonner TI, Brann MR (1988) Localization of a family of muscarinic receptor mRNAs in rat brain. J Neurosci 8:4646-4652.

Couch JV (1982) Fundamentals of statistics for the behavioral sciences, pp 266-270. New York: St. Martin.

Crino PB, Vogt BA, Volicer L, Wiley RG (1990) Cellular localization of serotonin $1 \mathrm{~A}, \mathrm{BB}$ and uptake sites in cingulate cortex of the rat. J Pharmacol Exp Ther 252:651-656.

Ehlert FJ, Kokka N, Fairhurst AS (1980) Altered $\left[{ }^{3} \mathrm{H}\right]$ quinuclidinyl benzilate binding in the striatum of rats following chronic cholinesterase inhibition with diisopropylfluorophosphate. Mol Pharmacol 17:24-30.

Gabriel M, Miller JD, Saltwick SE (1977) Unit activity in cingulate cortex and anteroventral thalamus of the rabbit during differential conditioning and reversal. J Comp Physiol Psychol 91:423-433.

Gabriel M, Foster K, Orona E (1980a) Interaction of laminae of the cingulate cortex with the anteroventral thalamus during behavioral learning. Science 208:1050-1052.

Gabriel M, Foster K, Orona E, Saltwick SE, Stanton M (1980b) Neuronal activity of cingulate cortex, anteroventral thalamus, and hippocampal formation in discriminative conditioning: encoding and extraction of the significance of conditional stimuli. In: Progress in psychobiology and physiological psychology, Vol 9 (Sprague J, Epstein AN, eds), pp 125-232. New York: $\Lambda$ cademic.

Gabriel M, Lambert RW, Foster K, Orona E, Sparenborg S, Maiorca RR (1983) Anterior thalamic lesions and neuronal activity in the cingulate and retrosplenial cortices during discriminative avoidance behavior in rabbits. Behav Neurosci 97:675-696.

Gabriel M, Kubota Y, Shenker J (1988) Limbic circuit interactions during learning. In: Information processing by the brain (Markowitsch H, ed), pp 39-63. Toronto: Huber.

Gabriel M, Sparenborg S, Kubota Y (1989) Anterior and medial thalamic lesions, discriminative avoidance learning, and cingulate cortical neuronal activity in rabbits. Exp Brain Res 76:441-457.

Ganguly DK, Das M (1979) Effects of oxotremorine demonstrate presynaptic muscarinic and dopaminergic receptors on motor terminals. Nature 278:645-646.

Hoover DB, Baisden RH (1980) Localization of putative cholinergic neurons innervating the anteroventral thalamus. Brain Res Bull 5: 519-524.

Kuhar MJ, Murrin LC (1978) Sodium-dependent, high affinity choline uptake. J Neurochem 30:15-21.

Lubar JF (1964) Effect of medial cortical lesions on the avoidance behavior of the cat. J Comp Physiol Psychol 58:38-46.

Lubar JF, Perachio AA (1965) One-way and two-way learning and transfer of an active avoidance response in normal and cingulectomized cats. J Comp Physiol Psychol 60:46-52.

Mash DC, Flynn DD, Potter LT (1985) Loss of M2 muscarinic receptors in the cerebral cortex in Alzheimer's disease and experimental cholinergic denervation. Science 228:1115-1117.

Peretz E (1960) The effects of lesions of the anterior cingulate cortex on the behavior of the rat. J Comp Physiol Psychol 53:540-548.

Plager MD, Vogt BA (1988) Mu and delta opioid receptor binding peaks and kappa homogeneity in the molecular layers of rat hippocampal formation. Brain Res 460:150-154.

Saper CB (1984) Organization of cerebral cortical afferent systems in the rat. II. Magnocellular basal nucleus. J Comp Neurol 222:313342.

Schiller GD (1979) Reduced binding of $\left({ }^{3} \mathrm{H}\right)$-quinuclidinyl benzilate associated with chronically low acetylcholinesterase activity. Life Sci 24:1159-1164.

Sikes RW, Vogt BA (1987) Afferent connections of anterior thalamus in rats: sources and association with muscarinic acetylcholine receptors. J Comp Neurol 256:538-551.

Sofroniew NV, Priestly JV, Consolazione A, Ekenstein F, Cuello AC (1985) Cholinergic projections from the midbrain and pons to the thalamus in the rat identified by combined retrograde tracing and choline acetyltransferase immunohistochemistry. Brain Res 329:213223.

Takeyasu K, Uchida S, Noguchi Y, Fujita N, Saito K, Hata F, Yoshida 
H (1979) Changes in brain muscarinic acetylcholine receptors and behavioral responses to atropine and apomorphine in chronic atropine-treated rats. Life Sci 25:585-592.

Uchida S, Takeyasu K, Matsuda T, Yoshida H (1979) Changes in muscarinic acetylcholine receptors of mice by chronic administration of diisopropylfluorophosphate and papaverine. Life Sci 24:1805-1812.

Unnerstall JR, Kopajtic TA, Kuhar MJ (1984) Distribution of $\alpha_{2}$ agonist sites in the rat and human central nervous system: analysis of some functional, anatomic correlates of the pharmacological effects of clonidine and related adrenergic agents. Brain Res Rev 7:69-101.

Vogt BA (1991) The role of layer I in cortical function. In: Cerebral cortex, Vol 9 (Peters A, Jones EG, eds), pp 49-80. New York: Plenum.

Vogt BA, Burns DL (1988) Experimental localization of muscarinic receptor subtypes to cingulate cortical afferents and neurons. J Neurosci 8:643-652.

Vogt BA, Hedberg TG (1988) Autoradiographic localization of muscimol and baclofen binding sites in rodent cingulate cortex. Exp Brain Res 71:208-214.

Vogt BA, Sikes RW (1990) Lateral magnocellular thalamic nucleus in rabbits: architecture and projections to cingulate cortex. J Comp Neurol 299:64-74.

Vogt BA, Rosene DL, Peters A (1981) Synaptic termination of thalamic and callosal afferents in cingulate cortex of the rat. $J$ Comp Neurol 201:265-283.

Vogt BA, Sikes RW, Swadlow HA, Weyand TG (1986) Rabbit cingulate cortex: cytoarchitecture, physiological border with visual cortex, and afferent cortical connections of visual, motor, postsubicular, and intracingulate origin. J Comp Neurol 248:74-94.

Wenk G, Hepler D, Olton D (1984) Behavior alters the uptake of $\left[{ }^{3} \mathrm{H}\right]$ choline into acetylcholinergic neurons of the nucleus basalis magnocellular and medial septal area. Behav Brain Res 13:129-138.

Westlind A, Grynfard M, Hedlund B, Bartfai T, Fuxe K (1981) Muscarinic supersensitivity induced by septal lesion or chronic atropine treatment. Brain Res 225:131-141.

Young WS III, Kuhar MJ (1981) Neurotensin receptor localization by light microscopic autoradiography in rat brain. Brain Res 206: 273-285. 